\title{
Different Strategies of Active Learning in Introductory Astronomy Course
}

\author{
Yudhiakto Pramudya $a^{\text {a,b,1 }}$ \\ ${ }^{a}$ Magister Pendidikan Fisika Universitas Ahmad Dahlan, Jalan Pramuka 42, Yogyakarta 55161, Indonesia \\ ${ }^{a}$ Pusat Studi Astronomi, Universitas Ahmad Dahlan, Yogyakarta, Indonesia \\ 1ypramudya@uad.ac.id
}

\begin{abstract}
Introductory Astronomy course for undergraduate physics education students is usually lack of hands-on activities in the teaching process. In this paper, we discuss different strategies to get more interaction between the students and teacher. The active learning strategies were the review assignment, group presentation, battle game, and moon observation. The final project was writing popular articles about astronomy topics because the students should be ready to become science communicators as a part of physics teacher's duties. The technology role became important to share ideas, assignments and browsing the materials for the articles. The students gave positive responses in the motivation and understanding of particular topics. However, we will discuss some factors that have to be considered as potential problems to deliver active learning.
\end{abstract}

Index Terms - active learning, hands-on activities, project based learning, astronomy.

\section{Introduction}

The astronomy education in the college level of nonastronomy major usually covers basic concept of astronomy. The more challenges rise when the class is delivered in English for non-native English speaker students. Hence, it needs creative strategies to overcome the lack of students' involvement in the classroom.

One of the strategies is the implementation of active learning method. The active learning is able to improve the lower order thinking into the higher order thinking based on the Bloom's taxonomy. The higher order thinking in the higher education need to be more focused on [1]. Cooperative learning can be used to support the active learning activities. In the cooperative learning, students work and learn in groups. The students have to show their collaborative skill in order to complete the assignment that is given by the lecturer [2].

Another method that can be employed in the active learning is project based learning. Students have to finish their project related to the topics of the course. By engaging the students to investigate the topics, the lecturer can motivate the students to study better. The project based learning has to be well prepared by the lecturer. The project then needs to be designed properly to assist the students to have activities that produce a product related to it [3]. Hence, the project can have different level of complexity. The lecturer needs to be aware of the time scale for the project completion. To assist the students do their project, the lecturer have to prepare the material for the project [4].

\section{Active Learning Strategies}

\section{A. E-learning and review assignments}

The first strategy is online learning and review assignment. The students were given the task to learn about the sun from the articles in internet, youtube videos, or books. They had to write short reviews from those resources in English on the lecturer's blog. This was the individual assignment. However, they could use the same resources but the review must be unique.

Table 1 The Review Assignment

\begin{tabular}{|c|c|}
\hline Resources & Number of students \\
\hline Youtube & 14 \\
\hline Article in the web & 8 \\
\hline Book & 2 \\
\hline
\end{tabular}

The students need to complete the assignment within a week. After the assignment was due, the students were given short quiz about the sun in the classroom. Based on the resources, the students' work distribution is shown in Table 1. Most of the students prefer to study by watching youtube videos. However, only 10 of the total students were able to write reviews. The rest still have problem on how to write good review. The common problem is that the students only copy the transcript on the video or the text of the article to be reviews.

\section{B. The group presentation}

The class was divided into 6 groups. Each group consisted of four students. The method of group organization was based on Numbered Heads Together approach. Here, each of the students was assigned to a specific number. Students with the same number were in the same group.

Each group had to present different topics of astronomy. They were the telescope mounting, refractor telescope, reflector telescope, catadioptric telescope, binocular, and constellation. The topics were chosen to prepare the students for the next active learning assignment, which is observation assignment.

Every presentation was using the power point for about 15 minutes. The other groups who were not presenting got the opportunity to ask several questions. They also had to evaluate the presentation skill and the content. The final score of presentation skill is a combination of scores 
between the peer evaluation and the lecturer evaluation as shown in Figure 1.

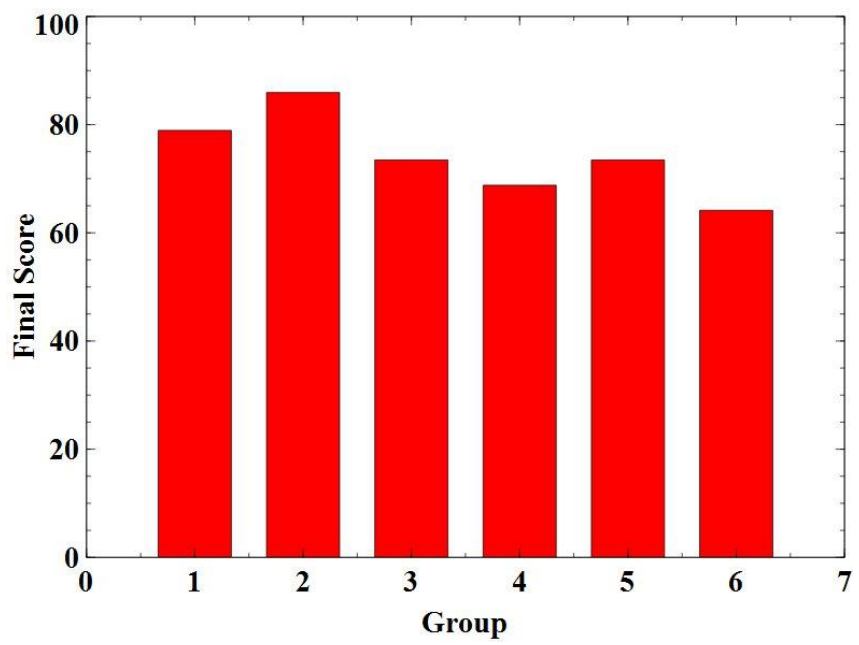

\section{The Moon observation assignment}

The students need to have experience hands on activities. The activity was the moon observation. The class was divided in the same group from the previous assignment. Before the observation begun, the lecturer gave a short lecture about the telescope and the moon observation. Therefore, the students had studied on those topics in the previous assignment.

Each group had to report their observation on the paper sheet as shown in Figure 2. The main item on the report sheet is the moon sketch that was seen through the telescope. Unfortunately, the weather was cloudy. Hence, they only had limited time to observe.

Fig. 1 The final score of presentation delivered by each group.

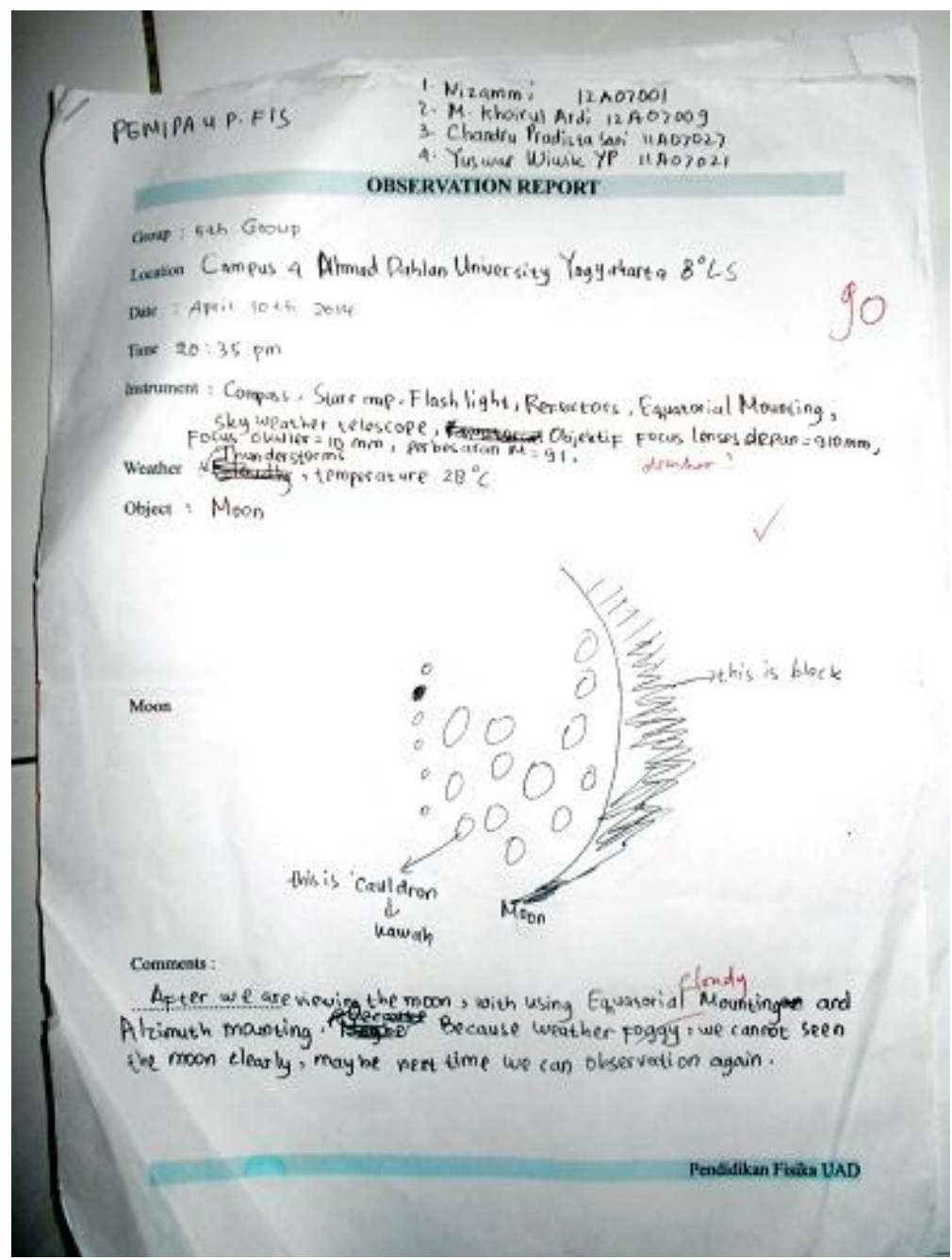

Fig. 2 The moon observation report that has information of place, date, time, weather condition, instruments and the moon sketch. 


\section{The battle game}

Beside students' participation, the active learning needs a fun environment in the classroom. Hence, we introduced the game approach to deliver the topics of meteoroid, comet, and asteroid. Once again, the class was divided into 6 groups. Those groups were formed into 3 clusters related to the 3 topics mentioned above.

In the battle style, two groups in the cluster will compete by answer questions from the lecturer. If a group fails to answer correctly, other groups in the cluster will have opportunity to answer. However, a group can skip the turn to answer and give the turn to another group. The correct answer was worth 20 points but the wrong answer was worth -10 points. The game became more fun but was also complicated since we combined it with the snake and ladder board game. Before the group answered question, they had to throw the dice and to move the pin according to the number that was shown on the dice.

The students had already prepared the topics by studying the material from the lecturer and the other resources e.g internet, books. The understanding of the topics can be evaluated on the final exam. The students had to answer the problems related to the meteoroid, comet, and asteroid. The average score related to the difference between meteoroid and asteroid was 5.22 out of 10 with the standard deviation of 0.52 . The average score related to the structure of the comet tails was 3.61 out of 10 with the standard deviation of 0.36 .

\section{E. The popular astronomy book assignment}

The grand strategy for active learning is writing project. The class was divided into 12 small groups. Each group consisted of 2 students. There were 12 astronomy topics that can be chosen by each group. They are Moon, Voyager, Temperature of the Universe, Mars, Jupiter, Saturn, Pleiades, Light Velocity, Pluto, Gravity, Apollo 11, and Zodiac Constellation. The article is intended to be the popular article since there are few popular astronomy books in Indonesia.

The purpose of this project was to prepare the students to be a good physics teacher as well as science communicators. Besides, the students needed the opportunity to train their writing skills. Since this was the first writing project for them, they could write the article in Bahasa Indonesia.

In the end of the semester, they had to finish their work. The grading process was based on the structure, originality, and ability to communicate the topics to the public. The average score was 91.25 out of 100 with the standard deviation of 4.24. To investigate the students' understanding related to their chosen topics, the specific problem related to the topics was given in the final exam. The students had to write short summaries of their article in English. The score for this answer in the final test was based on usage of English and the structure. The average score was 8.97 out of 10 with the standard deviation of 0.90 .

\section{Problem on implementing the strategies}

The common problem of the active learning is consuming time. For the strategies that were implemented inside the classroom, the lecturer had to manage the time since there was another class afterward. This happened when we implemented the presentation and the battle game. However, the moon observation assignment, which was the outside classroom activity, also had the time problem. Since the observation site was located far from the students' house, they had to avoid travelling back home late night.

\section{The Impact}

The active learning in the introductory astronomy course was able to enhance the students' interest to study astronomy. A number of students initiated to form the study forum of astronomy since they thought that they need more knowledge beyond the classroom. They also prepared to build the homemade telescopes. There were students who will go to their teaching job abroad. They planned to introduce the homemade telescopes and the observation techniques to their students. The students who had the interest on photography became more active in the discussion and practice on the astrophotography. In term of science communication, there was a student who has interest in disseminating the astronomy news on the social media and local radio.

\section{Conclusions}

The different strategies of active learning on the introductory astronomy course have been implemented. The cooperative learning and project based learning approach were employed. However, the time consuming is still uneasy problem to be solved. Another problem of evaluation has also risen since the lecturer usually got absorbed into the active learning preparation but not in the evaluation process. However, the active learning was able to enhance the students' interest not only to study more advanced topics but also disseminate and teach astronomy to the public.

\section{Acknowledgment}

This work is supported by Pendidikan Fisika, Magister Pendidikan Fisika, and Pusat Studi Astronomi Universitas Ahmad Dahlan.

\section{References}

[1] Tim Fasilitator Alfhe UAD, "Modul pelatihan active learning for higher education (ALFHE)," Yogyakarta, 2004.

[2] A. Suprijono, Cooperative learning, $12^{\text {th }}$ ed., Yogyakarta, Pustaka Pelajar, pp.54-55, 2012.

[3] P. C. Blumenfeld, E. Soloway, R. W. Marx, J. S. Krajcik, M. Guzdial, and A. Palincsar, "Motivating project based learning: sustaining the doing, supporting the learning," Educational Psychologist, vol. 26, no. 3\&4, pp 369-398, 1991.

[4] J. E. Millls and D. F. Treagust, "Engineering education - is problem based learning or project based learning the answer?," Australian Journal of Engineering Education, vol. 2003, pp. 2-16, 2003. 